\title{
Korean Medication Algorithm for Bipolar Disorder 2014: comparisons with other treatment guidelines
}

This article was published in the following Dove Press journal:

Neuropsychiatric Disease and Treatment

26 June 2015

Number of times this article has been viewed

Jong-Hyun Jeong,' Jeong Goo Lee, ${ }^{2,3}$ Moon-Doo Kim, ${ }^{4}$ Inki Sohn, ${ }^{5}$ Se-Hoon Shim, ${ }^{6}$ Hee Ryung Wang,' Young Sup Woo,' Duk-In Jon, ${ }^{7}$ Jeong Seok Seo, ${ }^{8}$ Young-Chul Shin, ${ }^{9}$ Kyung Joon Min, ${ }^{10}$ Bo-Hyun Yoon, "'Won-Myong Bahk'

'Department of Psychiatry, College of Medicine, The Catholic University of Korea, Seoul, ${ }^{2}$ Department of Psychiatry, Haeundae Paik Hospital, College of Medicine, Paik Institute for Clinical Research, Inje University, ${ }^{3}$ Department of Health Science and Technology, Graduate School of Inje University, Busan, ${ }^{4}$ Department of Psychiatry, Jeju National University Hospital, Jeju, ${ }^{5}$ Department of Psychiatry, Keyo Hospital, Keyo Medical Foundation, Uiwang, ${ }^{6}$ Department of Psychiatry, Soonchunhyang University Cheonan Hospital, College of Medicine, Soonchunhyang University, Cheonan, ${ }^{7}$ Department of Psychiatry, Sacred Heart Hospital, College of Medicine, Hallym University, Anyang, ${ }^{8}$ Department of Psychiatry, Konkuk University Chungju Hospital, School of Medicine, Konkuk University, Chungju, 'Department of Psychiatry, Kangbuk Samsung Hospital, School of Medicine, Sungkyunkwan University, Seoul, ${ }^{10}$ Department of Psychiatry, Chung-Ang University Hospital, College of Medicine, Chung-Ang University, Seoul, "Department of Psychiatry, Naju National Hospital, Naju, Korea

Correspondence: Bo-Hyun Yoon Department of Psychiatry, Naju National Hospital, I328-31, Senam-ro, Sanpo-myeon, Naju 520-833, Korea

Tel +82613134114

Fax+82613304150

Emailyoonbh@chol.com

Won-Myong Bahk

Department of Psychiatry, Yeouido St Mary's Hospital, College of Medicine, The Catholic University of Korea, 10, 63-ro, Yeongdeungpo-gu, Seoul I50-7I3, Korea

Tel +82 23779 ।05।

Fax +82 27806577

Email wmbahk@catholic.ac.kr
Abstract: Our goal was to compare the recommendations of the Korean Medication Algorithm Project for Bipolar Disorder 2014 (KMAP-BP 2014) with other recently published guidelines for the treatment of bipolar disorder. We reviewed a total of four recently published global treatment guidelines and compared each treatment recommendation of the KMAP-BP 2014 with those in other guidelines. For the initial treatment of mania, there were no significant differences across treatment guidelines. All recommended mood stabilizer (MS) or atypical antipsychotic (AAP) monotherapy or the combination of an MS with an AAP as a first-line treatment strategy for mania. However, the KMAP-BP 2014 did not prefer monotherapy with MS or AAP for dysphoric/ psychotic mania. Aripiprazole, olanzapine, quetiapine, and risperidone were the first-line AAPs in nearly all of the phases of bipolar disorder across the guidelines. Most guidelines advocated newer AAPs as first-line treatment options in all phases, and lamotrigine in depressive and maintenance phases. Lithium and valproic acid were commonly used as MSs in all phases of bipolar disorder. As research evidence accumulated over time, recommendations of newer AAPs such as asenapine, paliperidone, lurasidone, and long-acting injectable risperidone - became prominent. This comparison identifies that the treatment recommendations of the KMAP-BP 2014 are similar to those of other treatment guidelines and reflect current changes in prescription patterns for bipolar disorder based on accumulated research data. Further studies are needed to address several issues identified in our review.

Keywords: bipolar disorder, pharmacotherapy, treatment algorithm, guideline comparison, KMAP-2014

\section{Introduction}

Bipolar disorder is characterized by diverse symptoms such as manic, depressive and mixed symptoms, and by recurrent patterns that cause challenges for treatment. Beginning in the 1990s, medical practice has shifted from experience-based to more evidence-based approaches. ${ }^{1}$ This trend has contributed to the development of treatment algorithms or clinical practice guidelines in psychiatric fields, ${ }^{2}$ including several treatment algorithms for bipolar disorder. ${ }^{3-7}$

However, the medical situation differs across countries; at times, the use of treatment guidelines may be constrained by cultural differences in clinical environments and medical situations, or by the culture-specific needs of clinicians and patients.

In Korea, a medication algorithm project (Korean Medication Algorithm Project for Bipolar Disorder, KMAP-BP) was initiated in 2001 and KMAP-BP was published in 2002 (KMAP-BP 2002), with its feasibility confirmed. ${ }^{8}$ Revised versions of KMAP-BP were released in 2006 and 2010. ${ }^{9-11}$ However, newer atypical antipsychotics (AAPs) and 
mood stabilizers (MSs) were introduced for the treatment of bipolar disorder, and the mood-stabilizing effect of AAPs was demonstrated.

To reflect the current changes in treatment strategies for bipolar disorder, the previous algorithm was revised, resulting in the publication of the KMAP-BP in 2014 (KMAP-BP 2014). ${ }^{12}$ In the current article, we compare the recommendations of KMAP-BP 2014 with those of other recently published global treatment guidelines (British Association for Psychopharmacology Guidelines for Treatment of Bipolar Disorder [BAP], Canadian Network for Mood and Anxiety Treatments Clinical Guidelines for the Management of Patients with Bipolar Disorder [CANMAT], National Institute for Health and Clinical Excellence Clinical Guideline for Bipolar Disorder [NICE], The World Federation of Societies of Biological Psychiatry Guidelines for Biological Treatment of Bipolar Disorder [WFSBP]). ${ }^{13-18}$ By identifying similarities and differences across treatment guidelines, our goal was to identify potential deficiencies in KMAP-BP $2014^{12}$ that would require additional attention or supplementary information, enhancing the usefulness of the KMAP-BP 2014 guidelines to clinical practice.

\section{Treatment guidelines as comparison targets \\ British Association for Psychopharmacology Guidelines for Treatment of Bipolar Disorder}

The British Association for Psychopharmacology constructed a set of guidelines based on the American Psychiatric Association Practice Guidelines for Bipolar Disorder, revised in 2002. ${ }^{19}$ The BAP adapted the American guidelines with the aim of guiding clinical decision-making in Britain and published these revisions in 2009 as the British Association for Psychopharmacology Guidelines for Treatment of Bipolar Disorder 2009 (BAP 2009). ${ }^{13}$ BAP 2009 consists of a list of clinical guidelines (Part 1) and their key points and supporting evidence (Part 2). It provides an evaluation of the supporting evidence; evidence is categorized as ranging from Category I (the most powerful evidence) to Category IV (the weakest). In addition, the strength of each recommendation is categorized from Grade A (the strongest recommendation) to Grade D (the weakest). The guidelines reflect the consensus of experts and a wide range of feedback. The BAP 2009 also provides basic information to patients and caregivers about diagnosis and treatment (Table 1).

\section{Canadian Network for Mood and Anxiety Treatments Clinical Guidelines for the Management of Patients with Bipolar Disorder}

The Canadian Psychiatric Association and the Canadian Network for Mood and Anxiety Treatments collaborated to publish evidence-based clinical guidelines for bipolar disorder in $1997 . .^{20}$ The guidelines were subsequently revised in $2005,{ }^{21} 2007,,^{22} 2009,{ }^{23}$ and $2013^{14}$ to reflect new evidence. CANMAT is a set of evidence-based treatment guidelines reflecting a comprehensive literature review. The treatment recommendations are categorized into four levels based on the strength of supporting evidence (Table 1).

\section{National Institute for Health and Clinical Excellence Clinical Guideline for Bipolar Disorder (NICE clinical guideline I85)}

NICE guideline has published numerous treatment guidelines, and among them is a set of guidelines for bipolar disorder that are based on a comprehensive literature review. The first edition of the NICE guidelines for bipolar disorder was published in $2006,{ }^{24}$ with a subsequent revision in $2014 .{ }^{15}$ Because the NICE guidelines are intended to serve a group of professionals working in various psychiatric fields, they provide relatively simple recommendations pertaining to the

Table I Summary of recent bipolar disorder treatment guidelines

\begin{tabular}{llll}
\hline Organization & Publication date & Audience & Methodology \\
\hline KMAP-BP & $2014^{12}$ & Psychiatrists & Expert consensus \\
BAP & $2009^{13}$ & Psychiatrists & Evidence-based \\
& $2013^{14}$ & Primary care physicians & \\
CANMAT & $2014^{15}$ & Psychiatrists & Evidence-based \\
NICE & 2009 (acute mania, mixed, rapid cycling) ${ }^{16}$ & Psychiatrists & Evidence-based \\
WFSBP & Primary care physicians & Evidence-based \\
& 2013 (maintenance) $^{18}$ & Psychiatrists & Primary care physicians \\
\end{tabular}

Abbreviations: KMAP-BP, Korean Medication Algorithm Project for Bipolar Disorder; BAP, British Association for Psychopharmacology; CANMAT, Canadian Network for Mood and Anxiety Treatments; NICE, National Institute for Health and Clinical Excellence; WFSBP, World Federation of Societies of Biological Psychiatry. 
level of diagnosis and treatment, and do not clearly define the strength of evidence or clearly differentiate among treatment recommendations (Table 1).

\section{The World Federation of Societies of Biological Psychiatry Guidelines for Biological Treatment of Bipolar Disorder}

The World Federation of Societies of Biological Psychiatry developed guidelines for bipolar disorder based on a comprehensive literature review. Guidelines addressing the depressive episode were published in $2002,{ }^{25}$ followed by guidelines for the manic episode in $2003,{ }^{26}$ and for maintenance therapy in 2004. ${ }^{27}$ Revisions were released in 2009 (manic episode), ${ }^{16}$ 2010 (depressive episode), ${ }^{17}$ and 2013 (maintenance therapy) ${ }^{18}$ to reflect new evidence. Treatment recommendations are categorized according to five levels depending on the strength of the supporting evidence (Table 1).

\section{Development of the KMAP-BP 20I 4}

The KMAP-BP $2014^{12}$ guidelines reflect expert consensus. This revised edition of the Korean Medication Algorithm for Bipolar Disorder used the same framework as the KMAP-BP 2010 (the second revision of the algorithm). ${ }^{11}$ The survey questionnaire that was used for the KMAP-BP 2014 included many of the same questions used in the KMAP-BP $2010^{11}$ but also contained several modifications. The 2014 edition featured newly added questions regarding treatment strategies for manic/hypomanic episodes, mixed/psychotic mania, depressive episodes, rapid cycling, and maintenance. It also added new questions pertaining to safety and compliance issues, and to strategies for special situations. The final 56-item questionnaire consisted of seven parts. The nine-point scale from the RAND Corporation ${ }^{4}$ was used to evaluate the adequacy of each treatment option. The survey was sent to a review panel of 110 Korean psychiatrists with extensive clinical experience and academic achievements in bipolar disorder. Reflecting a variety of medical contexts, the reviewers' affiliations included university hospitals, general hospitals, mental hospitals, and private psychiatric clinics. Seventy-three out of the 110 reviewers worked at university hospitals, 24 at general hospitals/mental hospitals, and 13 in private clinics. Sixty-four out of the 110 (58.21\%) responded to the survey questionnaire; of these, 42 were at university hospitals, 19 at general hospitals/mental hospitals, and four in private psychiatric clinics.

By estimating the means and 95\% confidence intervals (CIs) for each question item, we classified each treatment opinion into one of three categories based on the lowest CI category: 6.5 or greater for first-line treatment, 3.5-6.5 for second-line treatment, and lower than 3.5 for third-line treatment. If a first-line option was recommended by $50 \%$ or more of the experts, it was labeled as a "treatment of choice". The study was conducted in accordance with the Declaration of Helsinki, and the study protocol was approved by the Institutional Review Board of Yeouido St Mary's Hospital.

\section{Comparisons of recommendations across treatment guidelines}

\section{Acute mania/hypomania}

Initial treatment

For acute euphoric/classic mania, MS monotherapy (lithium or valproic acid) and a combination of MS and AAP are preferred as the first-line treatments in KMAP-BP 2014. ${ }^{12}$ The combination of MS and AAP is preferred in mixed and psychotic mania, and AAP monotherapy is a first-line treatment strategy in psychotic mania. The treatment strategy for hypomanic episodes is a monotherapy of MS or AAP. In KMAP-BP 2014, ${ }^{12}$ the combination of MS and AAP is the treatment of choice in all three types of mania (euphoric, mixed, and psychotic).

These recommendations are in line with the other treatment guidelines. However, other guidelines recommend not only the combination of AAP and MS but also AAP or MS monotherapies as first-line strategies in mixed/psychotic mania. ${ }^{13,16}$

The WFSBP guidelines ${ }^{22}$ recommend valproic acid as the only first-line MS medication; this result seems to reflect concerns regarding the safety of lithium. However, the guidelines advise caution in using valproic acid to treat females because of the risk of polycystic ovarian syndrome. ${ }^{13,16,23}$

In the KMAP-BP 2014, ${ }^{12}$ lithium and valproic acid are the preferred MS agents; this choice is consistent with the results of other previous guidelines. ${ }^{13,14}$ However, the newly published NICE guidelines do not recommend lithium or valproic acid as first-line treatment strategies in drug-naïve manic patients. This discrepancy is thought to be related to the fact that the NICE guidelines target a group of professionals working in various psychiatric fields, and hence provide relatively simply recommendations for diagnosis and treatment rather than offering the full range of treatments differentiated in accordance with supporting evidence and recommendation strength.

Aripiprazole, olanzapine, quetiapine, and risperidone are the first-line AAPs in euphoric, mixed, and psychotic mania, and risperidone is preferred as the second-line AAP for hypomanic episodes. ${ }^{12}$ These recommendations for manic 
Table 2 Treatment of acute euphoric/classic mania across practice guidelines

\begin{tabular}{|c|c|c|c|}
\hline Guidelines & First-line treatment & Next-step intervention & Later intervention \\
\hline KMAP-BP $2014^{12}$ & $\mathrm{Li}, \mathrm{Val}, \mathrm{Li}$ or $\mathrm{Val}+\mathrm{AAP}$ & $\begin{array}{l}\text { Li or Val + AAP, Li or Val + } \\
\text { two AAPs, Val + Li + AAP }\end{array}$ & $\begin{array}{l}\text { Two AAPs + Li + Val, Li + } \\
\text { Val + other AAP }\end{array}$ \\
\hline BAP $2009^{13}$ & $\begin{array}{l}\text { Mild: AP or Val or Li (or CBZ) } \\
\text { Severe: AP or Val (if required IM: } \\
\text { AP or BZ) }\end{array}$ & $\mathrm{Li}$ or $\mathrm{Val}+\mathrm{AP}$ & $\mathrm{ECT}$ or $\mathrm{CLZ}$ \\
\hline CANMAT $2013^{14}$ & $\begin{array}{l}\text { Li, Val, OLZ, RIS, QTP, QTPXR, } \\
\text { ARP, ZIP, ASP, PAL } \\
\text { Adjunctive with MS: RIS, QTP, } \\
\text { OLZ, ARP, ASP }\end{array}$ & CBZ, ECT, HP, Li + Val & $\begin{array}{l}C P Z, C L Z, \text { OXC, tamoxifen, } \\
\text { cariprazine, Li or VAL }+H P, \\
L i+C B Z \text {, adjunctive tamoxifen }\end{array}$ \\
\hline NICE $2014^{15}$ & $\begin{array}{l}\text { Without AM: HP, OLZ, QTP, OLZ } \\
\text { With Li: optimization, adding HP, } \\
\text { OLZ, QTP, RIS }\end{array}$ & Alternative AP or adding $\mathrm{Li}$ or $\mathrm{Val}$ & ECT \\
\hline WFSBP $2009^{16}$ & $\begin{array}{l}\text { Monotherapy with CE I and RG A } \\
\text { such as Val, ARP, ZIP, and RIS }\end{array}$ & $\begin{array}{l}\text { Optimize dosage; switch to } \\
\text { another first-line agent; in severe } \\
\text { mania, consider combination }\end{array}$ & $\begin{array}{l}\text { Add-on with first-line agent; } \\
\text { combination of two first-line } \\
\text { choices }\end{array}$ \\
\hline \multicolumn{4}{|c|}{$\begin{array}{l}\text { Abbreviations: KMAP-BP 2014, Korean Medication Algorithm Project for Bipolar Disorder 20I4; BAP 2009, The British Association for Psychopharmacology Guidelines } \\
\text { for Treatment of Bipolar Disorder 2009; CANMAT 2013, Canadian Network for Mood and Anxiety Treatments Clinical Guidelines for the Management of Patients with } \\
\text { Bipolar Disorder 20I3; NICE 2014, National Institute for Health and Clinical Excellence Clinical Guideline for Bipolar Disorder 20I4; WFSBP 2009, World Federation of } \\
\text { Societies of Biological Psychiatry Guidelines for Biological Treatment of Bipolar Disorder } 2009 \text { (treatment of acute mania); Li, lithium; Val, various kinds of valproic acids; } \\
\text { AAP, atypical antipsychotic; AP, antipsychotics; CBZ, carbamazepine; IM, intramuscular formulation; BZ, benzodiazepine; ECT, electroconvulsive therapy; CLZ, clozapine; } \\
\text { OLZ, olanzapine; RIS, risperidone; QTP, quetiapine; QTPXR, quetiapine XR; ARP, aripiprazole; ZIP, ziprasidone; ASP, asenapine; PAL, paliperidone; HP, haloperidol; CPZ, } \\
\text { chlorpromazine; OXC, oxcarbazepine; AM, antimanic agents; CE, categories of evidence; RG, recommendation of grade. }\end{array}$} \\
\hline
\end{tabular}

episodes are in line with the other treatment guidelines. ${ }^{13,14,16}$ Additionally, CANMAT $2013^{14}$ recommends monotherapy of ziprasidone (also in WFSBP 200916), asenapine, and paliperidone, and adjunctive asenapine with MS as firstline treatment strategies for treating euphoric/classic mania. Haloperidol mono- and adjunctive therapy are also primarily recommended in NICE 2014. ${ }^{15}$

KMAP-BP 2014 and other guidelines recommend AAP therapy for mood stabilization, based on numerous published studies of AAP efficacy in treating manic/hypomanic episodes (Tables 2 and 3 ).

\section{Next-step strategy}

In cases of nonresponse or incomplete response to first-line strategies, guidelines recommend switching or adding another first-line agent. KMAP-BP 2014 recommends switching from an MS or AAP to a different agent of the same type. ${ }^{12}$ Additionally, triple combinations such as lithium + two AAPs or lithium + valproic acid + AAP are suggested as next-step interventions in KMAP-BP 2014. Other guidelines are not substantially different, but CANMAT $2013^{14}$ recommends carbamazepine, which is not a first-line treatment strategy, as a next-step intervention. Additionally, asenapine, paliperidone, and electroconvulsive therapy (ECT) are highly recommended by CANMAT 2013. ${ }^{14}$

When MS and AAP combination therapy results in incomplete efficacy in treating mixed/psychotic mania, KMAP-BP 2014 recommends changing the specific MS or AAP, or adding another MS or AAP. ${ }^{12}$ However, because the other guidelines do not provide separate recommendations for the treatment of

Table 3 Treatment of mixed/psychotic mania across practice guidelines

\begin{tabular}{|c|c|c|c|}
\hline Guidelines & First-line treatment & Next-step intervention & Later intervention \\
\hline KMAP-BP $2014^{12}$ & $\begin{array}{l}\text { Mixed mania: Val or } \mathrm{Li}+\mathrm{AAP} \\
\text { Psychotic mania: Val or } \mathrm{Li}+\mathrm{AAP}, \mathrm{AAP}\end{array}$ & $\begin{array}{l}\mathrm{Li} \text { or } \mathrm{Val}+\mathrm{AAP}, \mathrm{Li} \text { or } \mathrm{Val}+ \\
\text { two AAPs, Val + } \mathrm{Li}+\mathrm{AAP}\end{array}$ & $\begin{array}{l}\text { Two AAPs + Li + Val, } \mathrm{Li}+ \\
\mathrm{Val}+\text { other AAP }\end{array}$ \\
\hline BAP $2009^{13}$ & $\begin{array}{l}\text { Same as for euphoric mania; AAP in } \\
\text { psychotic mania }\end{array}$ & Same as for euphoric mania & Same as for euphoric mania \\
\hline CANMAT $2013^{14}$ & Not mentioned & & \\
\hline NICE $2014^{15}$ & Same as for euphoric mania & Same as for euphoric mania & Same as for euphoric mania \\
\hline WFSBP $2009^{16}$ & Val, AAP (OLZ, ZIP, ARP) & RIS, CBZ & \\
\hline
\end{tabular}

Abbreviations: KMAP-BP 2014, Korean Medication Algorithm Project for Bipolar Disorder 2014; BAP 2009, The British Association for Psychopharmacology Guidelines for Treatment of Bipolar Disorder 2009; CANMAT 2013, Canadian Network for Mood and Anxiety Treatments Clinical Guidelines for the Management of Patients with Bipolar Disorder 2013; NICE 2014, National Institute for Health and Clinical Excellence Clinical Guideline for Bipolar Disorder 20I4; WFSBP 2009, World Federation of Societies of Biological Psychiatry Guidelines for Biological Treatment of Bipolar Disorder 2009 (treatment of acute mania); Val, various kinds of valproic acids; Li, lithium; AAP, atypical antipsychotic; OLZ, olanzapine; ZIP, ziprasidone; ARP, aripiprazole; RIS, risperidone; CBZ, carbamazepine. 
mixed/psychotic mania, direct comparison between KMAP-BP 2014 and the other guidelines is not possible.

In cases of incomplete response to second-line strategies, next-step interventions vary among the guidelines. However, ECT and clozapine are recommended in most guidelines, while chlorpromazine, tamoxifen, and cariprazine are recommended only in CANMAT $2013^{14}$ (Tables 2 and 3).

\section{Bipolar depression}

\section{Initial treatment}

KMAP-BP 2014 divides bipolar depression into categories of mild, moderate, severe, and psychotic. ${ }^{12} \mathrm{MS}$ monotherapy, or AAP in combination with MS or lamotrigine, is the first-line strategy for mild-to-moderate episodes of bipolar depression. In severe depression without psychotic features, MS in combination with AAP or antidepressants (ADs) is preferred. Lamotrigine can be combined with AAP in severe bipolar depression. AAP + MS, AAP + lamotrigine, AAP + $\mathrm{AD}, \mathrm{AAP}+\mathrm{MS}+$ lamotrigine, $\mathrm{AAP}+\mathrm{AD}+\mathrm{MS}$, and $\mathrm{AAP}+$ $\mathrm{AD}+$ lamotrigine are first-line treatment strategies for psychotic depression.

Valproic acid, lithium, and lamotrigine are rated as firstline MS treatments for bipolar depression. Preferred AAPs for bipolar depression are quetiapine, aripiprazole, and olanzapine. However, ziprasidone, risperidone, amisulpride, blonanserin, and paliperidone are second-line AAPs. If AD is needed in bipolar depression, bupropion, (es)citalopram, and sertraline are the first-line drugs, and mirtazapine and venlafaxine are other options for severe depression.

The BAP 2009 guidelines ${ }^{13}$ primarily recommend quetiapine and lamotrigine as monotherapeutic agents for mild-to-moderate bipolar depression, and selective serotonin reuptake inhibitors (SSRIs) are also recommended in combination with MS or AAP. ECT is a first-line treatment strategy for severe bipolar depression. In WFSBP 2010, quetiapine monotherapy, adjunctive quetiapine, an olanzapinefluoxetine combination, olanzapine, lamotrigine, lamotrigine + lithium, and valproic acid are recommended as first-line strategies. ${ }^{17}$ CANMAT $2013^{14}$ contains a wider range of therapeutic recommendations, with lithium, lamotrigine, quetiapine, quetiapine XR, MS + SSRI, olanzapine + SSRI, lithium + valproic acid, and MS + bupropion as first-line treatment strategies. The most recently published guideline, NICE 2014, ${ }^{15}$ recommends olanzapine + fluoxetine, quetiapine, olanzapine, and lamotrigine for bipolar depression patients who are not taking antimanic agents, depending on the patient's preferences and previous response to treatment. If a depressive episode develops during lithium therapy, optimization of lithium, olanzapine + fluoxetine, adjunctive quetiapine, adjunctive olanzapine, and adjunctive lamotrigine are first-line strategies.

The KMAP-BP 2014 is in line with the other guidelines regarding the increased preference for AAP without specifying that the recommendation by the other guidelines is restricted to some, but not all, AAPs in bipolar depression. Additionally and in contrast to KMAP-BP 2014 suggestions for first-line, the use of aripiprazole as combination therapy is labeled as not recommended by the updated CANMAT guidelines. ${ }^{14}$ It reflects some results that showed aripiprazole monotherapy to be not superior to placebo. ${ }^{28,29}$ However, another meta-analysis suggested that aripiprazole monotherapy could be effective for the treatment of acute depression because the combined data from two negative studies revealed a significant effect. ${ }^{30,31}$

Other findings that are shared by KMAP-BP 2014 and the other guidelines include the strict prohibition of AD monotherapy, an increasing preference for lamotrigine and AAP, and the wide recommendation of adjunctive AD use with MS or AAP. ${ }^{12-15,17}$ However, notable differences do exist between KMAP-BP $2014^{12}$ and other guidelines, ${ }^{13-15,17}$ in which MS monotherapy or AAP monotherapy is recommended as the first-line strategy based on research data. ${ }^{32-35}$ Even though the use of MS and AAP monotherapy for bipolar depression is supported by higher degrees of evidence, KMAP-BP 2014 prefers the combination therapy for severe episodes of depression with or without psychotic features (Table 4). This may be because a high proportion (64\%) of Korean experts who participated in KMAP-BP 2014 work at university hospitals; their primary interests may lie in treatment-resistant cases, which generally require combination therapies. Moreover, there are methodological differences between KMAP-BP $2014^{12}$ and other guidelines ${ }^{13-15,17}$ (expert consensus vs evidence-based). However, polypharmaceutical approaches to psychotropic medication appear to be increasingly common in clinical practice, ${ }^{36}$ suggesting that it is difficult to apply research-based findings to real clinical fields.

\section{Next-step strategy}

Regardless of the clinical situation, KMAP-BP $2014^{12}$ prefers adjunctive use of another medication over switching medications. Adding lamotrigine or an AAP is the preferred treatment strategy when there is insufficient response to treatment with MS alone. This strategy is also the first-line treatment for use in individuals who respond poorly to a combination of MS + AD or MS + AAP for moderate-to-severe episodes, as is the substitution of lamotrigine for an MS. Adding lamotrigine is another preferred strategy if there is inadequate response to the combination of MS + AAP. 
Table 4 Treatment of bipolar depression across practice guidelines

\begin{tabular}{|c|c|c|c|}
\hline Guidelines & First-line treatment & Next-step intervention & Later intervention \\
\hline KMAP-BP $2014^{12}$ & $\begin{array}{l}\text { Mild to moderate: MS, MS + AAP, } \\
\text { AAP + LTG } \\
\text { Nonpsychotic severe: MS + AAP, } \\
\text { LTG + AAP, MS + AD } \\
\text { Psychotic: AAP + (MS or LTG or AD), } \\
\text { AAP + MS + LTG, AAP + AD + MS } \\
\text { (or LTG) }\end{array}$ & $\begin{array}{l}\text { Mild to moderate: AAP, LTG, add AAP or } \\
\text { MS or LTG, change AAP } \\
\text { Nonpsychotic severe: add AAP or MS or } \\
\text { LTG or AD, change MS to LTG } \\
\text { Psychotic: add MS or LTG or AD, change } \\
\text { AAP, change MS to LTG }\end{array}$ & $\begin{array}{l}\text { Add or change } \mathrm{AAP} \text { or MS or LTG } \\
\text { or } \mathrm{AD} \text {, add stimulant or thyroid } \\
\text { hormone, buspirone, } E C T \text {, or } C L Z\end{array}$ \\
\hline BAP $2009^{13}$ & $\begin{array}{l}\text { Mild and/or previous mood instability: } \\
\text { QTP or LTG } \\
\text { Moderate: QTP or LTG, SSRI or other } \\
\text { AD (not TCA) } \\
\text { Consider ECT in severe depression }\end{array}$ & Add antimanic agent if BP-I & \\
\hline CANMAT $2013^{14}$ & $\begin{array}{l}\text { Li, LTG, QTP, QTPXR, Li or Val + } \\
\text { SSRI, OLZ + SSRI, Li + Val, Li or } \\
\text { Val + BUP }\end{array}$ & $\begin{array}{l}\text { Val, lurasidone, QTP + SSRI, Li or } \\
\text { Val + LTG, adjunctive MDF, Li or Val + } \\
\text { lurasidone }\end{array}$ & $\begin{array}{l}\text { CBZ, OLZ, ECT, Li + CBZ, Li + } \\
\text { pramipexole, } \mathrm{Li} \text { or Val + VEN, Li + } \\
\text { MAOI, Li or Val or AAP + TCA, Li or } \\
\text { Val or CBZ + SSRI + LTG, QTP + LTG }\end{array}$ \\
\hline NICE $2014^{15}$ & $\begin{array}{l}\text { Without AM: OLZ + FX, QTP, OLZ, } \\
\text { LTG } \\
\text { With MS: optimization, adjunctive } \\
\text { OLZ + FX, adjunctive QTP, adjunctive } \\
\text { OLZ, adjunctive LTG }\end{array}$ & Adding LTG & \\
\hline WFSBP $2010^{17}$ & $\begin{array}{l}\text { QTP, adjunctive QTP, OFC, OLZ, } \\
\text { LTG, LTG + Li, Val }\end{array}$ & $\begin{array}{l}\text { Optimization of first-line treatment, QTP, } \\
\text { add CBZ, Li, MDF + Li/Val/ADs, ECT }\end{array}$ & \\
\hline
\end{tabular}

Abbreviations: KMAP-BP 2014, Korean Medication Algorithm Project for Bipolar Disorder 20I4; BAP 2009, The British Association for Psychopharmacology Guidelines for Treatment of Bipolar Disorder 2009; CANMAT 2013, Canadian Network for Mood and Anxiety Treatments Clinical Guidelines for the Management of Patients with Bipolar Disorder 20I3; NICE 20I4, National Institute for Health and Clinical Excellence Clinical Guideline for Bipolar Disorder 20I4; WFSBP 20I0, World Federation of Societies of Biological Psychiatry Guidelines for Biological Treatment of Bipolar Disorder 2010 (treatment of acute bipolar depression); MS, mood stabilizer; AAP, atypical antipsychotic; LTG, lamotrigine; AD, antidepressant; ECT, electroconvulsive therapy; CLZ, clozapine; QTP, quetiapine; SSRI, selective serotonin reuptake inhibitor; TCA, tricyclic antidepressant; BP-I, bipolar I disorder; Li, lithium; QTPXR, quetiapine XR; Val, various kinds of valproic acids; OLZ, olanzapine; BUP, bupropion; MDF, modafinil; CBZ, carbamazepine; VEN, venlafaxine; MAOI, monoamine oxidase inhibitor; AM, antimanic agents; FX, fluoxetine; OFC, olanzapine-fluoxetine combination.

As next-step treatments, WFSBP $2010^{17}$ recommends the optimization of first-line medications, quetiapine + carbamazepine (or lithium), modafinil + valproic acid $+\mathrm{AD}$, and ECT. CANMAT $2013^{14}$ generally recommends combination therapy (such as quetiapine + SSRI, lamotrigine + lithium [or valproic acid], and adjunctive modafinil) over monotherapy for next-step intervention. Valproic acid, lurasidone, and adjunctive lurasidone also serve as potential second-line strategies under these guidelines. In NICE 2014, adding lamotrigine is a second-line strategy. ${ }^{15}$ Recent guidelines have dropped several strategies that were recommended in earlier guidelines, such as adjunctive thyroid hormone, adding clozapine, light therapy, other psychostimulants, and calcium channel blockers ${ }^{12-15,17}$ (Table 4).

\section{Rapid cycling}

For treating rapid-cycling patients, regardless of their current episodes, an AAP monotherapy and a combination of MS and AAP are first-line treatment strategies, as recommended by KMAP-BP 2014. ${ }^{12}$ However, the combination of lamotrigine and MS (or AAP) is potentially preferable during episodes of current depression. Adding another MS is the second-line strategy. These results are consistent with the findings of a previous study indicating that MS monotherapy has a limited effect on rapid cycling, and a combination of lithium and valproic acid is reported to be more effective than lithium or valproic acid monotherapy. ${ }^{37}$

Valproic acid and lithium are preferred, and quetiapine, olanzapine, and aripiprazole are additional first-line agents. Since the recent accumulation of data showing that AAP treatment is also effective for rapid-cycling bipolar disorder, ${ }^{30,38-41}$ the preference for AAP alone or in combination with MS has increased in the KMAP guidelines. Clozapine and ECT are evaluated as next-step interventions for individuals with unsuccessful prior treatments.

In contrast to KMAP-BP 2014, the other guidelines do not discuss strategies for treating rapid-cycling bipolar disorder. This may be due to the fact that the notion of rapid cycling has been established only fairly recently, and there is still insufficient research dealing with this phenomenon. Direct comparison across guidelines will be possible once a more comprehensive understanding of rapid cycling is achieved (Table 5). 
Table 5 Treatment of rapid cycling across practice guidelines

\begin{tabular}{|c|c|c|c|}
\hline Guidelines & First-line treatment & Next-step intervention & Additional comments \\
\hline KMAP-BP $2014^{12}$ & $\begin{array}{l}\text { Currently manic: MS + AAP, AAP } \\
\text { Currently depressed: MS + AAP, } \\
\text { AAP, MS, or AAP + LTG }\end{array}$ & $\begin{array}{l}\text { Currently manic: two MSs + AAP; } \\
\text { change AAP or MS, ECT } \\
\text { Currently depressed: change or add } \\
\text { MS, MS + AAP + LTG, add AD, ECT }\end{array}$ & $\begin{array}{l}\text { Change AAP to } C L Z \text { or add other } \\
A A P, M S \text { (including } C B Z \text { ), ECT }\end{array}$ \\
\hline BAP $2009^{13}$ & No recommendation & & \\
\hline CANMAT $2013^{14}$ & Not mentioned & & \\
\hline NICE $2014^{15}$ & $\begin{array}{l}\text { Same as with other types of } \\
\text { bipolar disorder }\end{array}$ & & \\
\hline WFSBP $2009^{16}$ & Not mentioned & & \\
\hline \multicolumn{4}{|c|}{$\begin{array}{l}\text { Abbreviations: KMAP-BP 2014, Korean Medication Algorithm Project for Bipolar Disorder 2014; BAP 2009, The British Association for Psychopharmacology Guidelines } \\
\text { for Treatment of Bipolar Disorder 2009; CANMAT 2013, Canadian Network for Mood and Anxiety Treatments Clinical Guidelines for the Management of Patients with } \\
\text { Bipolar Disorder 20I3; NICE 2014, National Institute for Health and Clinical Excellence Clinical Guideline for Bipolar Disorder 2014; WFSBP 2009, World Federation of } \\
\text { Societies of Biological Psychiatry Guidelines for Biological Treatment of Bipolar Disorder } 2009 \text { (treatment of acute mania); MS, mood stabilizer; AAP, atypical antipsychotic; } \\
\text { LTG, lamotrigine; ECT, electroconvulsive therapy; AD, antidepressant; CLZ, clozapine; CBZ, carbamazepine. }\end{array}$} \\
\hline
\end{tabular}

\section{Continuation and maintenance treatment}

In KMAP-BP $2014,{ }^{12}$ the preferred maintenance treatment strategies for recently manic bipolar I disorder are the combination of MS and AAP, MS monotherapy, or AAP monotherapy, with MS + lamotrigine and a combination therapy of two MSs recommended as second-line treatment strategies for recently manic patients. The preferred AAPs for maintenance treatment include quetiapine, aripiprazole, olanzapine, and risperidone, for use in monotherapy or in adjunctive use with MS. Ziprasidone, amisulpride, and blonanserin are recommended as strategies for next-step intervention.

If a manic episode develops during MS monotherapy, optimization of MS or adding an AAP is the preferred strategy. Quetiapine, aripiprazole, olanzapine, and risperidone are the preferred AAPs for this situation, and ziprasidone, amisulpride, and blonanserin are second-line agents. These preferences are similar to maintenance strategies with recently manic patients.

If the manic episode develops during AAP monotherapy, adding an MS is the first-line strategy. Combining two MSs, or switching from one MS to another, is offered as the nextstep intervention.

In KMAP-BP $2014,{ }^{12}$ the preferred maintenance strategy for recently depressed bipolar I disorder is the same as that of bipolar II disorder. The recommended first-line strategies are AAP + lamotrigine, $\mathrm{MS}+$ lamotrigine, $\mathrm{MS}+\mathrm{AAP}, \mathrm{MS}$ alone, AAP alone, and lamotrigine alone. However, secondline strategies are different for the two groups. In the case of bipolar I depression, two MSs or MS + AAP + lamotrigine is recommended. But for bipolar II depression, the preferred second-line strategies are AAP + MS + lamotrigine and MS + AD. The preferred first-line ADs are bupropion, escitalopram, and sertraline, with mirtazapine, fluoxetine, duloxetine, and venlafaxine serving as next-step candidates.
BAP 2009 recommends the following: if mania predominates, lithium, aripiprazole, quetiapine, valproic acid, and olanzapine are preferred, whereas if depression predominates, quetiapine and lamotrigine are first-line strategies. ${ }^{13}$ CANMAT 2013's first-line recommendations ${ }^{14}$ are similar to those in KMAP-BP 2014. CANMAT 2013 lists lamotrigine as a first-line drug for maintenance therapy, primarily for preventing depression. The previous version of CANMAT lists aripiprazole as a first-line drug to be used primarily for preventing mania. ${ }^{23}$ However, given that numerous studies indicate that aripiprazole is effective in preventing both mania and depression, ${ }^{42-45}$ the updated version of the guidelines suggests aripiprazole as a first-line medication for preventing both manic and depressive episodes. CANMAT 2013 recommends long-acting injectable risperidone as a first-line strategy, either as a monotherapy or in combination with MS, based on results showing its positive effects in preventing bipolar episodes. ${ }^{46,47}$ In WFSBP $2013,{ }^{18}$ aripiprazole, lamotrigine, lithium, and quetiapine are suggested as first-line drugs for preventing episodes of bipolar disorder. However, olanzapine and risperidone are next-step intervention strategies, a point on which WFSBP 2013 differs from the other guidelines. There are no published randomized controlled trials that evaluate bipolar maintenance treatment with risperidone, and some controversies about olanzapine's depression-preventing effect exist. ${ }^{18,48,49}$ Although many guidelines recommend olanzapine and risperidone as firstline drugs, clinicians might wish to consider this point.

NICE $2014,{ }^{15}$ the most recently published set of guidelines, recommends lithium as a first-line drug and valproic acid, olanzapine, and quetiapine as second-line medications. In addition, NICE 2014 also suggests AD, paliperidone, and ziprasidone as next-step strategies, recommendations that differ substantially from other guidelines. However, 
Table 6 Continuation and maintenance treatment across practice guidelines

\begin{tabular}{|c|c|c|c|}
\hline Guidelines & First-line treatment & Next-step intervention & Later intervention \\
\hline KMAP-BP $2014^{12}$ & $\begin{array}{l}\text { BP-I, recently manic: MS + AAP, MS, AAP } \\
\text { BP-I in breakthrough mania: optimization, } \\
\text { MS + AAP, add AAP } \\
\text { BP-II, recently hypomanic: MS, AAP, } \\
\text { MS + AAP } \\
\text { BP-I and BP-II, recently depressed: AAP } \\
\text { or MS + LTG, MS + AAP, MS, AAP, LTG }\end{array}$ & $\begin{array}{l}\text { BP-I, recently manic: MS + } \\
\text { LTG, two MSs } \\
\text { BP-I in breakthrough mania: Li } \\
\text { or Val + other MS, change MS } \\
\text { BP-I, recently depressed: two } \\
\text { MSs, MS + AAP + LTG } \\
\text { BP-II, recently hypomanic: } \\
\text { AAP + LTG, MS + LTG } \\
\text { BP-II, recently depressed: } \\
\text { AAP + MS + LTG, MS + AD }\end{array}$ & $\begin{array}{l}\text { Recently manic and hypomanic: AAP + LTG, } \\
\text { MS + AAP + LTG, AAP + MS + AD, LTG } \\
\text { BP-I in breakthrough mania: optimize/ } \\
\text { change MS } \\
\text { BP-I, recently depressed: AAP + AD, MS + } \\
\text { AAP + AD, MS + AD } \\
\text { BP-II, recently depressed: MS + } \\
\text { AAP + AD, AAP + AD + LTG }\end{array}$ \\
\hline BAP $2009^{13}$ & $\begin{array}{l}\text { If mania predominates: Li, ARP, QTP, Val, } \\
\text { OLZ } \\
\text { If depression predominates: QTP, LTG }\end{array}$ & $\begin{array}{l}\text { If mania predominates: CBZ } \\
\text { If depression predominates: } \mathrm{Li}\end{array}$ & Combination therapy: CLZ \\
\hline CANMAT $2013^{14}$ & $\begin{array}{l}\text { Li, LTG (limited efficacy in preventing } \\
\text { mania), Val, OLZ, QTP, RIS LAI, ARP, } \\
\text { adjunctive with MS: QTP, RIS LAI, ARP, ZIP }\end{array}$ & $\begin{array}{l}\text { CBZ, PAL, Li + Val, Li + CBZ, } \\
\mathrm{Li} \text { or Val + OLZ, Li + RIS, Li + } \\
\text { LTG, OLZ + FX }\end{array}$ & $\begin{array}{l}\text { Adjunctive phenytoin, adjunctive CLZ, } \\
\text { adjunctive ECT, adjunctive TP, adjunctive } \\
\text { omega-3-fatty acid, adjunctive OXC, or } \\
\text { adjunctive gabapentin } \\
\text { Adjunctive ASA }\end{array}$ \\
\hline NICE $2014^{15}$ & $\mathrm{Li}$ & Val, OLZ, QTP & \\
\hline WFSBP $2013^{18}$ & $\begin{array}{l}\text { ARP (mania and any episode), LTG } \\
\text { (depression and any episode), Li (any } \\
\text { episode), QTP (any episode) }\end{array}$ & $\begin{array}{l}\text { OLZ (mania and any episode), } \\
\text { RIS (mania and any episode) }\end{array}$ & $\begin{array}{l}\text { AD (depression), PAL (mania and any } \\
\text { episode), Val (depression), adjunctive ZIP } \\
\text { (mania and any episode) }\end{array}$ \\
\hline
\end{tabular}

Abbreviations: KMAP-BP 2014, Korean Medication Algorithm Project for Bipolar Disorder 2014; BAP 2009, The British Association for Psychopharmacology Guidelines for Treatment of Bipolar Disorder 2009; CANMAT 2013, Canadian Network for Mood and Anxiety Treatments Clinical Guidelines for the Management of Patients with Bipolar Disorder 2013; NICE 2014, National Institute for Health and Clinical Excellence Clinical Guideline for Bipolar Disorder 2014; WFSBP 2013, World Federation of Societies of Biological Psychiatry Guidelines for Biological Treatment of Bipolar Disorder 2013 (maintenance treatment); BP-I, bipolar I disorder; MS, mood stabilizer; AAP, atypical antipsychotic; BP-II, bipolar II disorder; LTG, lamotrigine; Li, lithium; Val, various kinds of valproic acids; AD, antidepressant; ARP, aripiprazole; QTP, quetiapine; OLZ, olanzapine; CBZ, carbamazepine; CLZ, clozapine; RIS LAI, risperidone long-acting injection; ZIP, ziprasidone; PAL, paliperidone; RIS, risperidone; FX, fluoxetine; ASA, asenapine; ECT, electroconvulsive therapy; TP, topiramate; OXC, oxcarbazepine.

it is worth noting that the NICE 2014 guidelines provide recommendations based on the experience and opinion of the Guideline Development Group, rather than on detailed assessments of evidence.

We found that in discussing maintenance treatments for bipolar disorder, numerous results are consistent across the various guidelines, including KMAP-BP 2014. However, despite the increased attention and research directed at bipolar II disorder, most guidelines, with the exception of KMAP-BP $2014^{12}$ and CANMAT 2013, ${ }^{14}$ do not describe detailed therapeutic recommendations pertaining to maintenance treatment of bipolar II disorder. Also noteworthy is the increasing preference over time for aripiprazole and lamotrigine as part of a maintenance strategy, likely due to new research findings and the accumulation of clinical experience (Table 6).

\section{Discussion}

Although various guidelines have been offered to improve clinical practice, their enforcement has been difficult to achieve because they have different characteristics in terms of their clarity, simplicity of recommendations, reliability, and use of evidence-based medicine. ${ }^{50,51}$

In this review, we compared the recommendations of KMAP-BP 2014 with those of other widely used treatment guidelines. For the initial treatment of mania, there are no substantial differences across treatment guidelines. All guidelines recommend MS alone, or AAP alone, or MS + AAP as first-line treatment strategy for mania. However, KMAP-BP 2014 differs from other guidelines in that it does not recommend monotherapy of MS or AAP for mixed/psychotic mania. Aripiprazole, olanzapine, quetiapine, and risperidone are the first-line AAPs for manic episodes across the guidelines, with ziprasidone recommended as an additional first-line drug in some guidelines. In cases of nonresponse or incomplete response, the guidelines recommend switching to or adding another first-line agent. The KMAP-BP 2014 guidelines recommend switching from one MS or AAP to another one. Additionally, triple combinations such as lithium + two AAPs or lithium + valproic acid + AAP are suggested as next-step interventions in KMAP-BP 2014. CANMAT 
2013 recommends carbamazepine as a next-step intervention. ECT and clozapine are recommended in most guidelines.

Monotherapy with MS or AAP is the first-line strategy for a mild episode of bipolar depression. In moderate-to-severe depression, MS + AAP, or MS + lamotrigine, or AAP + AD is preferred. Valproic acid, lithium, and lamotrigine are rated as first-line MSs, and quetiapine, aripiprazole, and olanzapine are rated as first-line AAPs for bipolar depression. The strict prohibition of AD monotherapy and an increasing preference for lamotrigine and AAP are found in all guidelines. However, adjunctive AD use with MS or AAP is more widely recommended. KMAP-BP 2014 prefers the adjunctive use of another medication rather than switching as the next-step strategy for depressive episodes.

AAP alone and MS + AAP are first-line treatment strategies for treating rapid cycling in KMAP-BP 2014. However, other guidelines do not discuss strategies for rapid cycling.

Among maintenance treatments, MS + AAP, MS alone, or AAP alone is the first-line strategy in KMAP-BP 2014. This is similar to other guidelines, although some of the other guidelines prefer MS, or AAP, or lamotrigine monotherapy. There is an increasing preference for aripiprazole and lamotrigine during maintenance.

There are no substantial differences between KMAP-BP 2014 and other treatment guidelines. In particular, the increased preference for AAP and lamotrigine patterns similarly in all the guidelines. However, a strong preference for combination therapy is characteristic of KMAP-BP 2014, predominantly in the treatment of dysphoric/psychotic mania and severe depression.

There may be several explanations for this. First, European guidelines tend to prefer monotherapy, but American guidelines take a more permissive stance on combination therapy. The recommendations in KMAP-BP 2014 may reflect the influence of results from frequently cited American studies. Second, it might be that many of the KMAP-BP 2014 experts are working in university hospital, where more treatment-resistant cases were treated.

While similarities between the KMAP-BP 2014 and the treatment algorithms may reflect the evidence base and consensus in some areas such as treatment of mania, areas where evidence are still sparse or lacking such as in rapid cycling, mixed mania, and treatment resistance, the guidelines often vary in their suggestions.

\section{Limitations}

KMAP-BP $2014^{12}$ guideline was an expert consensus guideline, but other guidelines ${ }^{13-18}$ compared were evidence-based one. Some treatment strategies in KMAP-BP 2014 may not have been rated as first-line options despite evidence demonstrating their effectiveness. Evidence-based treatment evaluation is a systematic process that critically evaluates the scientific evidence about a particular treatment. Evidence comes from many sources, including randomized clinical trials, cohort studies, observational case studies, and retrospective studies. These good evidences make clinicians to evaluate the actual effect of a treatment on patient outcomes. However, most of these experimental data in evidence-based guidelines are derived from randomized controlled trials and may not reflect the complexity of real clinical situations, which suggests that there may be some discrepancies between the findings of randomized controlled trials and the real-world practice.

KMAP-BP $2014^{12}$ has limitations as a set of expert consensus guidelines. Hence, we made efforts to compensate for these limitations by opening the public hearing at the Academic Conference of the Korean College of Neuropsychopharmacology, and by opening the results announcement and panel discussion at the Academic Conference of the Korean Society for Affective Disorders. Despite the limits of expert opinion, our current comparison shows that there are no major differences in overall treatment recommendations between KMAP-BP 2014 and other guidelines. Furthermore, the recommendations of KMAP-BP 2014 align well with current changes in the pharmacotherapy of bipolar disorder based on newer evidence. However, we also found some differences between KMAP-BP 2014 and other guidelines with respect to the recommended treatments for mixed/psychotic mania and severe depression. This likely reflects the controversial nature of the results in these areas; as relevant studies accumulate, they may prompt appropriate modifications to some of the guidelines. Finally, we have reason to believe that KMAP-BP 2014 provides useful information to Korean clinicians regarding their clinical decision-making, and that the guidelines are well administered in Korean clinical practice.

\section{Acknowledgments}

This study was supported by the Korean Society for Affective Disorders and the Korean College of Neuropsychopharmacology.

\section{Disclosure}

The authors do not have any conflicts of interest relevant to the conduct of this study or preparation of the manuscript. 


\section{References}

1. Evidence Based Medicine Working Group. Evidence-based medicine. A new approach to teaching the practice of medicine. JAMA. 1992;268(17):2420-2425.

2. American Psychiatric Association. Practice guideline for eating disorders. American Psychiatric Association. Am J Psychiatry. 1993;150(2): 212-228.

3. American Psychiatric Association. Practice guideline for the treatment of patients with bipolar disorder. American Psychiatric Association. Am J Psychiatry. 1994;151(12 suppl):1-36.

4. Sachs GS, Printz DJ, Kahn DA, Carpenter D, Docherty JP. The expert consensus guideline series: medication treatment of bipolar disorder 2000. Postgrad Med. 2000:1-104.

5. Kahn DA, Sachs GS, Printz DJ, Carpenter D, Docherty JP, Ross R. Medication treatment of bipolar disorder 2000: a summary of the expert consensus guidelines. J Psychiatr Pract. 2000;6(4):197-211.

6. Suppes T, Dennehy EB, Hirschfeld RM, et al; Texas Consensus Conference Panel on Medication Treatment of Bipolar Disorder. The Texas implementation of medication algorithms: update to the algorithms for treatment of bipolar I disorder. J Clin Psychiatry. 2005;66(7):870-886.

7. Goodwin GM. Evidence-based guidelines for treating bipolar disorder: recommendations from the British Association for Psychopharmacology. J Psychopharmacol. 2003;17(2):149-173. discussion 147.

8. The Executive Committee of Korean Bipolar Medication Algorithm Project for Bipolar Disorder. The Korean Medication Guideline for Bipolar Disorder 2002. Seoul Korea: Jungang Moonwhasa; 2002.

9. Jon DI, Bahk WM, Yoon BH, et al. Algorithm-driven treatment for bipolar disorder in Korea: clinical feasibility, efficacy, and safety. Int J Psychiatry Clin Pract. 2009;13(2):122-129.

10. Jon DI, Bahk WM, Yoon BH, et al. Revised Korean medication algorithm for bipolar disorder. World J Biol Psychiatry. 2009;10(4 pt 3): 846-855.

11. Shin YC, Min KJ, Yoon BH, et al. Korean medication algorithm for bipolar disorder: second revision. Asia Pac Psychiatry. 2013; 5(4):301-308

12. Woo YS, Lee JG, Jeong JH, et al. Korean medication algorithm project for bipolar disorder: third revision. Neuropsychiatr Dis Treat. 2015;11:493-506.

13. Goodwin GM. Evidence-based guidelines for treating bipolar disorder: revised second edition - recommendations from the British Association for Psychopharmacology. J Psychopharmacol. 2009;23(4):346-388.

14. Yatham LN, Kennedy SH, Parikh SV, et al. Canadian Network for Mood and Anxiety Treatments (CANMAT) and International Society for Bipolar Disorders (ISBD) collaborative update of CANMAT guidelines for the management of patients with bipolar disorder: update 2013. Bipolar Disord. 2013;15(1):1-44.

15. National Collaborating Centre for Mental Health. Bipolar Disorder: The Assessment and Management of Bipolar Disorder in Adults, Children and Young People in Primary and Secondary Care. Leicester UK: The British Psychological Society; The Royal College of Psychiatrists; 2014.

16. Grunze H, Vieta E, Goodwin GM, et al. The World Federation of Societies of Biological Psychiatry (WFSBP) guidelines for the biological treatment of bipolar disorders: update 2009 on the treatment of acute mania. World J Biol Psychiatry. 2009;10(2):85-116.

17. Grunze H, Vieta E, Goodwin GM, et al; WFSBP Task Force On Treatment Guidelines For Bipolar Disorders. The World Federation of Societies of Biological Psychiatry (WFSBP) guidelines for the biological treatment of bipolar disorders: update 2010 on the treatment of acute bipolar depression. World J Biol Psychiatry. 2010;11(2):81-109.

18. Grunze H, Vieta E, Goodwin GM, et al; WFSBP Task Force on Treatment Guidelines for Bipolar Disorders. The World Federation of Societies of Biological Psychiatry (WFSBP) guidelines for the biological treatment of bipolar disorders: update 2012 on the long-term treatment of bipolar disorder. World J Biol Psychiatry. 2013;14(3):154-219.

19. American Psychiatric Association. Practice guideline for the treatment of patients with bipolar disorder (revision). Am J Psychiatry. 2002;159 (4 suppl):1-50.
20. Sharma V, Yatham LN, Haslam DR, et al. Continuation and prophylactic treatment of bipolar disorder. Can J Psychiatry. 1997;42(suppl 2): 92S-100S.

21. Yatham LN, Kennedy SH, O'Donovan C, et al; Canadian Network for Mood and Anxiety Treatments. Canadian Network for Mood and Anxiety Treatments (CANMAT) guidelines for the management of patients with bipolar disorder: consensus and controversies. Bipolar Disord. 2005;7(suppl 3):5-69.

22. Yatham LN, Kennedy SH, O’Donovan C, et al; Guidelines Group, CANMAT. Canadian Network for Mood and Anxiety Treatments (CANMAT) guidelines for the management of patients with bipolar disorder: update 2007. Bipolar Disord. 2006;8(6):721-739.

23. Yatham LN, Kennedy SH, Schaffer A, et al. Canadian Network for Mood and Anxiety Treatments (CANMAT) and International Society for Bipolar Disorders (ISBD) collaborative update of CANMAT guidelines for the management of patients with bipolar disorder: update 2009 . Bipolar Disord. 2009;11(3):225-255.

24. National Collaborating Centre for Mental Health (UK). Bipolar Disorder: The Management of Bipolar Disorder in Adults, Children and Adolescents, in Primary and Secondary Care. Leicester UK: The British Psychological Society; The Royal College of Psychiatrists; 2006.

25. Grunze H, Kasper S, Goodwin G, et al; World Federation of Societies of Biological Psychiatry Task Force on Treatment Guidelines for Bipolar Disorders. World Federation of Societies of Biological Psychiatry (WFSBP) guidelines for biological treatment of bipolar disorders. Part I: Treatment of bipolar depression. World J Biol Psychiatry. 2002;3(3): 115-124.

26. Grunze H, Kasper S, Goodwin G, et al; WFSBP Task Force on Treatment Guidelines for Bipolar Disorders. The World Federation of Societies of Biological Psychiatry (WFSBP) guidelines for the biological treatment of bipolar disorders, part II: treatment of mania. World J Biol Psychiatry. 2003;4(1):5-13.

27. Grunze H, Kasper S, Goodwin G, Bowden C, Moller HJ. The World Federation of Societies of Biological Psychiatry (WFSBP) guidelines for the biological treatment of bipolar disorders, part III: maintenance treatment. World J Biol Psychiatry. 2004;5(3):120-135.

28. Cruz N, Sanchez-Moreno J, Torres F, Goikolea JM, Valenti M, Vieta E. Efficacy of modern antipsychotics in placebo-controlled trials in bipolar depression: a meta-analysis. Int J Neuropsychopharmacol. 2010; 13(1):5-14.

29. Selle V, Schalkwijk S, Vazquez GH, Baldessarini RJ. Treatments for acute bipolar depression: meta-analyses of placebo-controlled, monotherapy trials of anticonvulsants, lithium and antipsychotics. Pharmacopsychiatry. 2014;47(2):43-52.

30. Fountoulakis KN, Kontis D, Gonda X, Yatham LN. A systematic review of the evidence on the treatment of rapid cycling bipolar disorder. Bipolar Disord. 2013;15(2):115-137.

31. Vieta E, Valenti M. Pharmacological management of bipolar depression: acute treatment, maintenance, and prophylaxis. CNS Drugs. 2013; 27(7):515-529.

32. Calabrese JR, Bowden CL, Sachs GS, Ascher JA, Monaghan E, Rudd GD. A double-blind placebo-controlled study of lamotrigine monotherapy in outpatients with bipolar I depression. Lamictal 602 Study Group. $J$ Clin Psychiatry. 1999;60(2):79-88.

33. Calabrese JR, Keck PE Jr, Macfadden W, et al. A randomized, doubleblind, placebo-controlled trial of quetiapine in the treatment of bipolar I or II depression. Am J Psychiatry. 2005;162(7):1351-1360.

34. Thase ME, Macfadden W, Weisler RH, et al. Efficacy of quetiapine monotherapy in bipolar I and II depression: a double-blind, placebo-controlled study (the BOLDER II study). J Clin Psychopharmacol. 2006; 26(6):600-609.

35. Geddes JR, Calabrese JR, Goodwin GM. Lamotrigine for treatment of bipolar depression: independent meta-analysis and meta-regression of individual patient data from five randomised trials. $\mathrm{Br} J$ Psychiatry. 2009;194(1):4-9. 
36. Mojtabai R, Olfson M. National trends in psychotropic medication polypharmacy in office-based psychiatry. Arch Gen Psychiatry. 2010;67(1):26-36.

37. Calabrese JR, Shelton MD, Bowden CL, et al. Bipolar rapid cycling: focus on depression as its hallmark. JClin Psychiatry. 2001;62(suppl 14): 34-41.

38. Gonzalez-Pinto A, Tohen M, Lalaguna B, et al. Treatment of bipolar I rapid cycling patients during dysphoric mania with olanzapine. J Clin Psychopharmacol. 2002;22(5):450-454.

39. Langosch JM, Drieling T, Biedermann NC, et al. Efficacy of quetiapine monotherapy in rapid-cycling bipolar disorder in comparison with sodium valproate. J Clin Psychopharmacol. 2008;28(5):555-560.

40. Zupancic ML. Role of atypical antipsychotics in rapid cycling bipolar disorder: a review of the literature. Ann Clin Psychiatry. 2011; 23(2):141-149.

41. Muzina DJ, Momah C, Eudicone JM, et al. Aripiprazole monotherapy in patients with rapid-cycling bipolar I disorder: an analysis from a longterm, double-blind, placebo-controlled study. Int J Clin Pract. 2008;62(5): 679-687.

42. Buoli M, Serati M, Altamura AC. Is the combination of a mood stabilizer plus an antipsychotic more effective than mono-therapies in long-term treatment of bipolar disorder? A systematic review. J Affect Disord. 2014; 15(2-154):12-18.

43. de Bartolomeis A, Perugi G. Combination of aripiprazole with mood stabilizers for the treatment of bipolar disorder: from acute mania to long-term maintenance. Expert Opin Pharmacother. 2012;13(14): 2027-2036.

44. Gitlin M, Frye MA. Maintenance therapies in bipolar disorders. Bipolar Disord. 2012;14(suppl 2):51-65.
45. Salvi V, Cat Berro A, Bechon E, Bogetto F, Maina G. Litio e anticonvulsivanti nel trattamento della mania e nella profilassi delle ricorrenze [Lithium and anticonvulsants in the treatment of mania and in the prophylaxis of recurrences]. Riv Psichiatr. 2011;46(3):172-181. Italian.

46. QuirozJA, Yatham LN, Palumbo JM, Karcher K, Kushner S, KusumakarV. Risperidone long-acting injectable monotherapy in the maintenance treatment of bipolar I disorder. Biol Psychiatry. 2010;68(2):156-162.

47. Macfadden W, Alphs L, Haskins JT, et al. A randomized, double-blind, placebo-controlled study of maintenance treatment with adjunctive risperidone long-acting therapy in patients with bipolar I disorder who relapse frequently. Bipolar Disord. 2009;11(8):827-839.

48. Tohen M, Calabrese JR, Sachs GS, et al. Randomized, placebocontrolled trial of olanzapine as maintenance therapy in patients with bipolar I disorder responding to acute treatment with olanzapine. Am $J$ Psychiatry. 2006;163(2):247-256.

49. Tohen M, Greil W, Calabrese JR, et al. Olanzapine versus lithium in the maintenance treatment of bipolar disorder: a 12-month, randomized, double-blind, controlled clinical trial. Am J Psychiatry. 2005;162(7): 1281-1290.

50. Davis DA, Taylor-Vaisey A. Translating guidelines into practice. A systematic review of theoretic concepts, practical experience and research evidence in the adoption of clinical practice guidelines. CMAJ. 1997;157(4): $408-416$.

51. Solberg LI, Brekke ML, Fazio CJ, et al. Lessons from experienced guideline implementers: attend to many factors and use multiple strategies. Jt Comm J Qual Improv. 2000;26(4):171-188.
Neuropsychiatric Disease and Treatment

\section{Publish your work in this journal}

Neuropsychiatric Disease and Treatment is an international, peerreviewed journal of clinical therapeutics and pharmacology focusing on concise rapid reporting of clinical or pre-clinical studies on a range of neuropsychiatric and neurological disorders. This journal is indexed on PubMed Central, the 'PsycINFO' database and CAS,

\section{Dovepress}

and is the official journal of The International Neuropsychiatric Association (INA). The manuscript management system is completely online and includes a very quick and fair peer-review system, which is all easy to use. Visit http://www.dovepress.com/testimonials.php to read real quotes from published authors. 